\title{
EGb761 protects motoneurons against avulsion-induced oxidative stress in rats
}

\author{
Xiao Cheng ${ }^{1}$, Fo-Lin Liu'1, Jun Zhang², Lin-Lin Wang' ${ }^{1}$ Fang-lan Li', Shu Liu and Li-Hua Zhou*1
}

\begin{abstract}
Background: Root avulsion of the brachial plexus causes an oxidative stress reaction in the spinal cord and induces dramatic spinal motoneuron death, while EGb761 is a natural free radical cleaning agent. This study was designed to investigate the protective effects of intraperitoneally injected EGb761 against neural damage following brachial root avulsion.
\end{abstract}

Methods: The effect of EGb761 on avulsion-induced motoneuron injury was studied in 26 total groups of (n) rats, treated as follows. Animals in singular number groups received EGb761 $(50 \mathrm{mg} / \mathrm{kg} . \mathrm{d})$ and those in complex number groups received normal saline solution (i.p.), serving as controls. Groups 1-8 were used for the determination of nitric oxide (NO) levels in the serum and injured spinal cord at the $5 d, 2$ w, 4 w, and 6 w time points. Groups 9-16 were used for determination of constitutive nitric oxide synthase (cNOS) and inducible nitric oxide synthase (iNOS) levels in injured spinal cord at the $5 \mathrm{~d}, 2 \mathrm{w}, 4 \mathrm{w}$, and $6 \mathrm{w}$ time points. Groups 17-26 were used for determination of the number of neuronal nitric oxide synthase (nNOS)-positive and surviving motoneurons in injured C7 ventral horn at the $5 \mathrm{~d}, 2 \mathrm{w}$, $4 \mathrm{w}, 6 \mathrm{w}$ and $8 \mathrm{w}$ time points.

Results: Compared to control groups, the EGb761 treatment group not only had significant decreased levels of NO in serum at $2 \mathrm{w}$ and $6 \mathrm{w}$ after avulsion, but also had reduced levels of $\mathrm{NO}$ specifically in the spinal cord at $2 \mathrm{w}, 4 \mathrm{w}$ and $6 \mathrm{w}$. The cNOS activity in the spinal cord was also significant decreased at $2 \mathrm{w}$ and $4 \mathrm{w}$, while the iNOS activity in injured C6T1 spinal segments was reduced at $2 \mathrm{w}, 4 \mathrm{w}$ and $6 \mathrm{w}$. All together, the percentages of NADPH-d positive motoneurons in an injured C7 segment were down-regulated and the number of surviving motoneurons in injured C7 ventral horn was increased at $2 \mathrm{w}, 4 \mathrm{w}, 6 \mathrm{w}$ and $8 \mathrm{w}$ in treated versus untreated animals.

Conclusions: Intraperitoneal administration of EGb761 after root avulsion of the brachial plexus exerted protective effects by decreasing the level of NO in spinal cord and serum and the activity of cNOS and iNOS, easing the delayed motoneurons death. EGb761 should be considered in the treatment of brachial plexus nerve injuries.

\section{Introduction}

Brachial plexus injuries in adults are commonly caused by auto or motorcycle accidents. The treatment of this type of injury consists of nerve repair and nerve grafting for extraforaminal nerve root or trunk injury, and of neurotization or nerve transfer for nerve roots avulsion; however, the outcome of brachial plexus reconstruction and the restoration of shoulder and elbow function are often poor in spite of the sophistication of the various methods used[1,2]. The death of a major proportion of the innervating neuronal pool is likely to be the most fundamental

* Correspondence: zhoulih@mail.sysu.edu.cn

1 Department of Anatomy, Zhong Shan School of Medicine; Sun Yat-Sen University, No. 74 Zhong shan Road 2, Guangzhou 510080, PR China

Full list of author information is available at the end of the article neurobiological barrier to functional restitution because survival is an essential prerequisite for regeneration[3]. Currently the primary aim of management of root avulsion of the brachial plexus is motor recovery. However, 80-90\% of motoneurons have been shown to die after avulsion[4,5], complicating this goal. Immediate repair or nerve grafting offers some degree of protection to the motoneurons but is clinically limited, so there remains a need for medical approaches to maintain the viability of the injured motoneurons.

The Ginkgo biloba extract EGb761 is a standardized mixture of active substances obtained from green leaves of the Ginkgo biloba tree, composed of $24 \%$ flavonoid glycosides and 6\% terpenoids[6,7]. EGb761 has been reported to be a potent free radical scavenger and many 
studies have demonstrated that the compound affects hemodynamics, metabolism, and hemorrheology. Additionally, EGb761 has antioxidant properties and transmitter/receptor effects in the brain, spinal cord, peripheral nervous system, retina, vestibulocochlear apparatus and cardiovascular system[8-10]. The mechanism of EGb761 action in the central nervous system (CNS) is relatively well-studied, and the main effect it exerts seems to be related to its antioxidant properties. Recently, in vitro studies have shown that EGb761 has a protective effect against neuronal apoptotic death[11,12] and an inhibitory effect on the expression of inducible nitric oxide synthase (iNOS) and nitric oxide (NO) production [13]. Animal experiments have also shown that EGb761 can prevent neuronal damage after brain ischemia through the inhibition of NOS [14]. However, its potential effect in patients suffering from spinal cord injury (SCI) is still unknown. In our previous studies, de novo expression of neuronal NOS (nNOS) was observed in injured motoneurons, and the time course and density of nNOS expression both correlated well with the severity of motoneuron death following brachial root avulsion, in which the oxidant peroxynitrite played an important role $[15,16]$. This raises the question of whether EGb761 has a similar neuroprotective effect on avulsion-injured motoneurons. In the present study, we used EGb761 to treat rats immediately after avulsion injury. The effect of EGb761 was estimated according to the survival of injured motoneurons. The investigation of the protective mechanism of EGb761 was focused on the production of NO, and the activity of both nNOS and iNOS. Our present study found that EGb761 protects motoneurons against avulsion injury and that this neuroprotective effect was related to the reduction of both NO and NOS in the injured spinal cord.

\section{Materials and methods Animals and Surgery}

Adult male Sprague-Dawley rats (250-280 g) were obtained from the Laboratory Animal Center of Sun Yatsen University, and all procedures were approved by the Committee for the Use of Live Animals in Teaching and Research at Sun Yat-sen University. All rats had free access to standard rat chow and tap water. Rats were fed with standard rat diet routinely, but were deprived of food for $12 \mathrm{~h}$ before the first operation. All rats in the present study received root avulsion surgery. Spinal root avulsion surgery followed the procedures described in our previous publications $[4,17,18]$. Briefly, the rats were anesthetized with intramuscular injections of ketamine $(80 \mathrm{mg} / \mathrm{kg})$ and xylazine $(8 \mathrm{mg} / \mathrm{kg})$, and all nerve roots, including $\mathrm{C} 5, \mathrm{C} 6, \mathrm{C} 7, \mathrm{C} 8$ and $\mathrm{T} 1$ of the right brachial plexus, were separated under an Olympus surgical microscope. Extra-vertebral avulsion of the ventral and dorsal roots was carried out on $\mathrm{C} 5, \mathrm{C} 6, \mathrm{C} 7, \mathrm{C} 8$, and $\mathrm{T} 1$ by pull- ing the nerve root out with microhemostatic forceps. The avulsed ventral and dorsal roots together with the dorsal root ganglia were cut away from the distal ends of the spinal nerves and examined under the microscope to confirm the success of the surgery. All surgical instruments were appropriate for the size of each animal. The skin was then sutured, and long-acting penicillin (3,000,000 units, sc) was given after the surgery. The rats were allowed to recover until awake and returned to their cages.

\section{EGb761 treatment}

Rats received daily intraperitoneal (i.p.) injections of vehicle (saline) or EGb761 (50 mg/kg body weight). EGb761 treatment was started immediately after the root avulsion surgery. EGb761 was provided by Schwabe Pharmaceuticals (Karlsruhe, Germany). The extract is wellcharacterized[19] and is being used in ongoing clinical trials[20]. EGb761 was dissolved in physiological saline and the $\mathrm{pH}$ adjusted to 7.4. The survival time points were 5 days $(5 \mathrm{~d}), 2$ weeks $(2 \mathrm{w}), 4$ weeks $(4 \mathrm{w}), 6$ weeks $(6 \mathrm{w})$ and 8 weeks $(8 \mathrm{w})$ post-injury. The effect of EGb761 on avulsion-induced motoneuron injury was studied in the following experimental groups. Animals in Groups 1, 3, 5, $7,9,11,13,15,17,19,21,23$ and 25 received EGb761 while those in Groups 2, 4, 6, 8, 10, 12, 14, 16, 18, 20, 22, 24 and 26 received normal saline solution (i.p.), serving as controls. Groups 1-8 were used for determination of NO levels in the serum and injured spinal cord at the $5 \mathrm{~d}, 2 \mathrm{w}$, $4 \mathrm{w}$, and $6 \mathrm{w}$ time points. Groups 9-16 were used for determination of cNOS and iNOS levels in injured spinal cord at the $5 \mathrm{~d}, 2 \mathrm{w}, 4 \mathrm{w}$, and $6 \mathrm{w}$ time points. Groups $17-$ 26 were used for determination of the number of nNOSpositive and survival motoneurons in injured $\mathrm{C} 7$ ventral horn at the $5 \mathrm{~d}, 2 \mathrm{w}, 4 \mathrm{w}, 6 \mathrm{w}$ and $8 \mathrm{w}$ time points. Each treatment group included six to eight rats.

\section{Determination of NO level}

$24 \mathrm{~h}$ after the last EGb761 or saline administration, the rats were anesthetized with a lethal dose of $10 \%$ Chloral Hydrate and $1 \mathrm{ml}$ of blood was taken from the caudal vein, after which they were sacrificed by cervical dislocation. Using dorsal laminectomy, the spinal segments from $\mathrm{C} 5$ to $\mathrm{T} 1$ were identified and removed. The level of $\mathrm{NO}$ in spinal cord and serum was determined using a NO kit (Nanjing Jiancheng Institute of Biology and Engineering, Nanjing, China). Briefly, the method involved measuring the levels of NO metabolites (nitrite and nitrate), which are more stable than NO. We thus estimated the level of $\mathrm{NO}$ in the sample by determining total nitrate and nitrite concentration. The rationale for this method is based on the fact that nitrate reductase catalyzes the enzymatic conversion of nitrate to nitrite and determines total nitric oxide concentration. This step was followed by the colorimetric measurement of nitrite as an azo dye product of 
the Griess reaction. A two-step diazotization reaction occurs during the Griess reaction, wherein acidified nitrite produces a nitrosating agent that reacts with sulphanilic acid to produce the diazoniumion. This product is then coupled with $\mathrm{N}$-(1-naphthyl) ethylenediamine to form the chromophoric azo-derivative, which has a peak absorbance of $550 \mathrm{~nm}$. The NO level in spinal cord was expressed as $\mu \mathrm{mol} / \mathrm{g}$ of spinal cord protein. The NO level in serum was expressed as $\mu \mathrm{mol} / \mathrm{L}$ of serum[21].

\section{Determination of constitutive NOS (cNOS)}

Rats were killed by cervical dislocation $24 \mathrm{~h}$ after the last EGb761 or saline administration. Using dorsal laminectomy, the spinal segments from $\mathrm{C} 5$ to $\mathrm{T} 1$ were identified and removed[15,22,23]. Inducible NOS (iNOS) activity and total NOS activity in spinal cord were measured with a NOS kit (Nanjing Jiancheng Institute of Biology and Engineering, Nanjing, China), which assessed activity by measuring the conversion of $\mathrm{L}-\left[{ }^{14} \mathrm{C}\right]$-arginine to $\mathrm{L}-\left[{ }^{14} \mathrm{C}\right]-$ citrulline [24]. The total NOS activity was determined by incubating samples $(50 \mu \mathrm{L})$ for $15 \mathrm{~min}$ at $37^{\circ} \mathrm{C}$ in a reaction mixture containing buffer solution and $20 \mu \mathrm{M}$ nicotinamide adenine dinucleotide phosphate( $\beta$-NADPH), 1 $\mathrm{mM} \mathrm{CaCl}_{2}, 50 \mu \mathrm{M}$ tetrahydrobiopterin (BH4) and $1 \mu \mathrm{Ci} /$ $\mathrm{ml} \mathrm{L}-\left[{ }^{14} \mathrm{C}\right]$-arginine. Inducible NOS (iNOS) activity was measured by omitting calcium and adding $1 \mathrm{mM}$ EDTA to the reaction mixture $(50 \mu \mathrm{L})$ for $60 \mathrm{~min}$ at $37^{\circ} \mathrm{C}$. The reaction was stopped by the addition of $1 \mathrm{ml}$ of ice-chilled buffer containing $30 \mathrm{mM}$ HEPES and $3 \mathrm{mM}$ EDTA (pH 5.5), after which the reaction mix was applied to Dowex AG50W-X8 columns to remove $\mathrm{L}-\left[{ }^{14} \mathrm{C}\right]$-arginine. Columns were eluted two times with $0.5 \mathrm{ml}$ of distilled water and $\mathrm{L}-\left[{ }^{14} \mathrm{C}\right]$-citrulline was quantified using a liquid scintillation spectrophotometer. cNOS activity was computed by subtracting iNOS activity from total NOS activity. One unit $(\mathrm{U})$ of total NOS activity was defined as picomoles of $\mathrm{L}-\left[{ }^{14} \mathrm{C}\right]$-citrulline produced per minute per microgram protein/milliliter. The activity of cNOS in spinal cord was expressed as U/mg of spinal cord protein.

\section{NADPH-d histochemistry plus neutral red}

At the end of each survival time ( $5 \mathrm{~d}, 2 \mathrm{w}, 4 \mathrm{w}, 6 \mathrm{w}, 8 \mathrm{w})$, rats were anesthetized with a lethal dose of $10 \%$ Chloral Hydrate and perfused transcardially with saline, followed by $4 \%$ paraformaldehyde in $0.1 \mathrm{M} \mathrm{PB}(\mathrm{pH} 7.4)$. After perfusion, the vertebral column was dissected, and the spinal cord was removed. The $\mathrm{C} 7$ spinal segment was defined as the region between the uppermost root and lowermost root of the C7 nerve of the contralateral spinal cord. The C7 segment of the spinal cord of each animal was removed, fixed by immersion in fresh fixative overnight and cryoprotected in 30\% (v/v) phosphate-buffered sucrose overnight. Frozen transverse sections $(40 \mu \mathrm{m})$ were cut and collected in 0.01 M PB. Every third section from each animal was used for NADPH-d histochemistry plus neutral red counterstaining. We have previously shown that NADPH-d staining recognizes NOS-containing neurons under normal conditions, and that NADPH$\mathrm{d}$ labels the same population of lesioned motoneurons as both NOS-ICC and NOS in situ hybridization[4,23]. Neuronal NOS-containing neurons were stained with $\mathrm{NADPH}$-diaphorase (NADPH-d) following our previous studies $[15,23]$. Briefly, sections were incubated at $37^{\circ} \mathrm{C}$ for $1 \mathrm{~h}$ in $10 \mathrm{ml}$ of $0.1 \mathrm{M}$ Tris-HCL(PH 8.0) containing $0.2 \%$ Triton X100, $10 \mathrm{mg}$ NADPH (Sigma), $2.5 \mathrm{mg}$ nitroblue tetrazolium (NBT) at $37^{\circ} \mathrm{C}$ for $1 \mathrm{~h}$ and then washed with $0.1 \mathrm{M} \mathrm{PB}$ three times. The stained sections were mounted onto slides and counterstained with $1 \%$ neutral red (Sigma). These sections were used to count the numbers of nNOS-positive and surviving motoneurons.

\section{Counting of motoneurons}

Approximately thirty cross sections (of $40 \mu \mathrm{m}$ thickness a piece) of the $\mathrm{C} 7$ spinal segment could be obtained from each animal, and every third section was used for NADPH-d histochemistry plus neutral red counterstaining. In total, ten light microscopic images of the $\mathrm{C} 7$ ventral horn of these sections in each animal were captured $(20 \times$ and $40 \times$ lens) with a Lucida camera attached to a Leica DFC350FX/DMIRB microscope. Data quantification and analysis were performed by two independent persons, both of whom were blinded to the treatment groups and the previous studies[4,15,23]. In NADPH-d plus neutral red-stained sections, a motoneuron with a visible nucleus in the neutral red stain was counted as a surviving cell. The number of surviving motoneurons was quantified on both the intact side and the lesioned side of the $\mathrm{C} 7$ section. The number of surviving motoneurons on the contralateral intact side was set as $100 \%$. The surviving motoneruons on the lesioned side, including both the NADPH-d positive and the NADPH-d-negative but neutral red-stained motoneurons, were then counted. The number of surviving motoneurons ipsilaterally was expressed as a percentage of the number of surviving motoneurons contralaterally in the same C7 section[22,25]. The number of ipsilateral nNOS-positive motoneurons, represented by only the NADPH-d reactive motoneurons, was expressed as a percentage of the number of surviving motoneurons on the contralateral side of the same $\mathrm{C} 7$ section. The number of nNOS-positive or surviving motoneurons of each animal was expressed as the mean of the nNOS-positive or surviving motoneurons in the 10 serial C7 sections[15,23,25].

\section{Statistical analysis}

The statistical calculations and data handling were performed using SPSS version 16.0. All variables were expressed as medians, mean \pm standard deviation $(\mathrm{X} \pm$ 
$\mathrm{SE}$ ) with the range. A one-way ANOVA was applied to detect differences among groups followed by TukeyKramer multiple comparison tests. Differences were considered significant at $\mathrm{p}$ values $<0.05$.

\section{Results \\ Effect of EGb761 on NO levels in the serum and injured spinal cord}

Following spinal root avulsion, the levels of $\mathrm{NO}$ in the serum and spinal cord increased, reaching a maximum at $2 \mathrm{w}$ and then gradually descending until $6 \mathrm{w}$. The neuroprotective effect of EGb761 against avulsion injury was closely related to a reduction in nitric oxide production in the serum and injured spinal cord. In serum, EGb761 reduced nitric oxide levels at $2 \mathrm{w}$ and $6 \mathrm{w}$ but not at $4 \mathrm{w}$ (Fig. 1A) compared to saline controls, while NO levels in injured C6-T1 spinal segments of treated animals were reduced at every time point (Fig. 1B).

\section{Treatment with EGb761 regulated cNOS and iNOS activity in injured C6-T1 spinal segments}

Root avulsion also resulted in a change in cNOS and iNOS activity in injured C6-T1 spinal segments. The activity of cNOS gradually increased after spinal root avulsion, reaching a peak at $2 \mathrm{w}$, and then descended gradually until $6 \mathrm{w}$. Meanwhile, the activity of iNOS increased gradually from the $2 \mathrm{w}$ to $6 \mathrm{w}$. The activity of cNOS and iNOS were down-regulated in animals that had been administered EGb761. Quantitative analysis showed there were significant differences between the EGb761 treated group and the saline control group in the activity of cNOS in injured C6-T1 spinal segments at $2 \mathrm{w}$ and $4 \mathrm{w}$ but not $6 \mathrm{w}$ (Fig. 1C), while iNOS activity in injured C6-T1 spinal segments showed significant differences at each time point (Fig. 1D).

\section{Expression of nNOS in ipsilateral ventral horn motoneurons after EGb761 treatment}

There is no expression of nNOS in the undamaged ventral horn motoneurons of the spinal cord, but nNOS can be induced in motoneurons on the lesioned side following root avulsion. The number of nNOS positive motoneurons in the ipsilateral ventral horn increased rapidly to a peak at $2 \mathrm{w}$, and then decreased gradually at 4 $\mathrm{w}$ and $6 \mathrm{w}$, confirming our previous studies[4]. Following spinal root avulsion, nNOS labeling was widely distributed in almost every injured motoneuron and was evident in the somatic cytoplasm and dendrites (Fig. 1I, K, M), In EGb761 treated rats, expression of nNOS was significantly down-regulated. Fewer nNOS positive neurons, exhibiting weak staining in the soma, were observed on the lesioned side (Fig. 1J, L, N.) compared to the saline-treated controls. Quantitative analysis of NADPH$\mathrm{d}$-stained slides showed that the differences between the
EGb761 and saline-treated control group were significant $(\mathrm{P}<0.001)$ at every time point (Fig. 1E). Morphologically, many surviving motoneurons were NADPH-d-positive by histochemistry in the saline control group after injury. However, very few NADPH-d-positive motoneurons were observed at the same time point post-injury in the EGb761-treated group, and most of the remaining motoneurons were NADPH-d-negative.

\section{Survival of injured motoneurons after EGb761 treatment}

The loss of motoneurons in the C7 spinal segments following avulsion was apparent at the end of $2 \mathrm{w}$, and was accompanied by the rapid appearance of nNOS positive motoneurons. The loss of motoneurons sharply increased at the $4 \mathrm{w}$ and $6 \mathrm{w}$ time points $(\mathrm{Fig} 1 \mathrm{~K}-\mathrm{N})$, and the ipsilateral ventral horn showed signs of atrophy (Fig 1O), confirming our previous conclusions[4]. Quantitative analysis showed that the number of surviving motoneurons in the EGb761 treated group was higher than in the saline-treated group (Fig. 1F), and statistical analysis showed that the differences between the EGb761 and saline treated groups were significant at $2 \mathrm{w}, 4 \mathrm{w}$ and $6 \mathrm{w}$ $(\mathrm{P}<0.05)$. Morphologically, many of the remaining motoneurons were NADPH-d-positive in the saline control group by $6 \mathrm{w}$ post-injury, while fewer NADPH-dpositive motoneurons were found at this time point in the EGb761 treated group (Fig. 1M-N).

\section{Discussion}

The present study demonstrated that avulsion-induced motoneuron death was related to changes in nitric oxide production and NOS activity in injured spinal segments. Furthermore, we found that EGb761 prevented death of motoneurons by suppressing both iNOS and nNOS activity, thus reducing NO production in the injured spinal cord.

Extracts of Ginkgo biloba, such as EGb761, are commonly used to increase blood circulation and to protect the lipid portion of cellular membranes against damage induced by free radicals [26]. EGb761 has also been shown to enhance cognition by increasing synaptic plasticity in the hippocampus [27]. Additionally, EGb761 has been proven to have cardiovascular protective effects in myocardial ischemia-reperfusion injury mediated through targeting NOS and NO production in the injured central nervous system[28]. In accordance with our present data, pretreatment with EGb761 has been found to attenuate up-regulation of cNOS and iNOS in the brain and have neuroprotective effects in hyperthermic brain injury[29]. A previous report has also shown that inhibition of the up-regulation of NO produced by iNOS reduced apoptosis in traumatic SCI models[30]. In the present study, our findings suggest that EGb761 has a neuroprotective effect on avulsion-induced motoneuron 


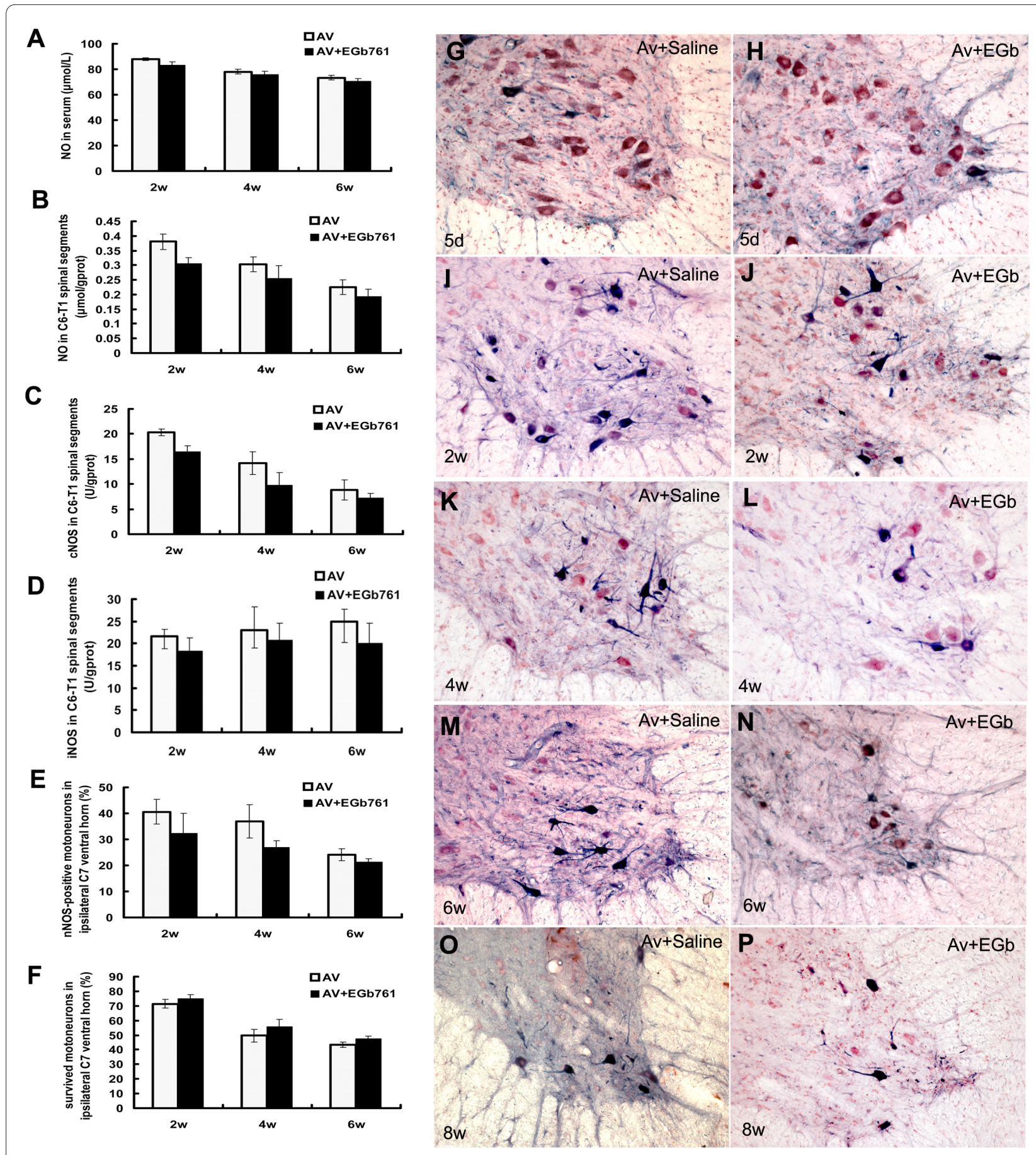

Figure 1 EGb761 protects motoneurons against avulsion-induced injury in rats. EGb761 protects motoneurons against avulsion-induced injury in rats. The neuroprotective effect of EGb761 against avulsion injury is associated with reductions in nitric oxide production and NOS expressions in the injured spinal cord. Compared to saline controls, EGb761 reduced nitric oxide levels in the serum at $2 \mathrm{w}$ and $6 \mathrm{w}$, but not at $5 \mathrm{~d}$ and $4 \mathrm{w}$ (Fig. A) and reduced nitric oxide levels in injured C6-T1 spinal segments at the $2 \mathrm{w}, 4 \mathrm{w}$ and $6 \mathrm{w}$ time points (Fig. B). EGb761 down-regulated cNOS levels (Fig. C), iNOS (Fig. D), nNOS levels in injured C6-T1 spinal segments (Fig. E,F), nNOS expressions in ipsilateral ventral horn motoneurons, and the death of injured motoneurons in ipsilateral ventral horn (Fig. H,J,L,N,P) induced by C5-T1 root avulsion injury. ${ }^{*} \mathrm{P}<0.01$ compared with the 'avulsion+saline (Av)' group at the same time point in graphic presentations of Fig. $\mathrm{G}, \mathrm{I}, \mathrm{K}, \mathrm{M}, \mathrm{O}$. Cross-sections of rat $\mathrm{C} 7$ segments from rats that underwent root avulsion and were injected with saline (Fig $\mathrm{G}, \mathrm{I}, \mathrm{K}, \mathrm{M}, \mathrm{O}$ ) or EGb761 (Fig. $\mathrm{H}, \mathrm{J}, \mathrm{L}, \mathrm{N}, \mathrm{P}$ ). Panels $(\mathrm{G})$ and $(\mathrm{H})$ were from rats surviving for $5 \mathrm{~d}$ after root avulsion. Panels (I) and $(J)$ were from rats surviving for $2 \mathrm{w}$ after root avulsion. Panels $(\mathrm{K})$ and $(\mathrm{L})$ were from rats surviving for $4 \mathrm{w}$ after root avulsion. Panels $(\mathrm{M})$ and $(\mathrm{N})$ were from rats surviving for $6 \mathrm{w}$ after root avulsion. Panels $(\mathrm{O})$ and $(\mathrm{P})$ were from rats surviving for $8 \mathrm{w}$ after root avulsion. NADPH-d plus neutral red stain $\times 10$ in Fig G-P. 
injury by significantly attenuating avulsion-induced upregulation of cNOS and iNOS activities in the spinal cord and $\mathrm{nNOS}$ expressions in injured motoneurons. Thus, it is possible that down-regulation of iNOS activity by EGb761 treatment might be an effective therapy for root avulsion injury.

Previous studies have shown that all three of the NOS isoforms, nNOS, iNOS, and eNOS, are up-regulated in the injured spinal cord[31]. Our present data confirmed that cNOS activity in injured spinal segments was markedly increased, regardless of whether there was treatment with EGb761. The cNOS consists of both nNOS and eNOS. In the present study we did not specifically quantify eNOS activity in injured spinal segments; however, the endothelial cells of blood vessels in the ipsilateral ventral horns were intensely stained in the NADPH-d reaction, indicating an up-regulation of eNOS in the injured spinal cord. A consensus has been reached that eNOS acts as a neuroprotective agent during the central nervous system injury[32], as high expression of eNOS in the endothelial cells of blood vessels may increase blood flow and therefore aid in the survival of injured neurons[33,34]. However, there are still debates about the role of nNOS in CNS injury. Many previous studies have considered NO produced by the nNOS to be neuroprotective[8], while other studies have found NO produced by nNOS to be neurotoxic [35]. Kwak et al., found that nNOS was actually protective against cell death at early stages of the injury and was constantly expressed in neurons, yet aberrant neuronal expression of nNOS could result in the loss of its neuroprotective role [36]. We agree with the opinion that factors such as the concentration range of NO, the redox state of the molecule, the cell type source, and the environment in which the NO is produced by nNOS appear to determine the role of nNOS in the CNS[37]. Normally there is no nNOS labeling by immunohistochemistry in spinal ventral horn motoneurons[38], but labeling is apparent in neurons located in the dorsal horn and around the central canal $[4,25]$. Our present study further confirmed that avulsion induced an increase in nNOS activity in ipsilateral ventral horn motoneurons. It is possible that the increase in nNOS activity in the first 2 weeks might play a neuroprotective role in avulsion injury, a notion based on a number of observations. First, motoneuron loss was mild within the first 2 weeks following avulsion with or without EGb761 treatments. Second, our previous study showed that down-regulation of nNOS protein in injured ventral horn motoneurons augmented the subsequent motoneuron loss[15,22]. Finally, the present data further demonstrated a remarkable loss in motoneurons beginning around 4 weeks after avulsion, a decline which was correlated not only with increased iNOS activity but also with decreased cNOS activity in the spinal cord.
In summary, the present study showed that avulsioninduced motoneuron death was correlated with increased iNOS activity and changes in cNOS activity in the injured spinal cord, as well as nNOS expression in injured motoneurons. EGb761 treatment diminished avulsioninduced motoneuron death by attenuating the avulsioninduced NO production and cNOS, iNOS activities in the injured spinal cord and nNOS expression in injured motoneurons.

\section{Competing interests}

The authors declare that they have no competing interests.

\section{Authors' contributions}

The authors of this paper indicated in the title made substantial contributions to the following tasks of research: initial conception and design (XC, LFL, JZ, LLW, FLL, SL, LHZ); administrative, technical, or material support (XC, LFL, JZ, LLW, FLL, LHZ); acquisition of data (XC, LFL, JZ, LLW, FLL, SL, LHZ); laboratory analysis and interpretation of data (XC, LFL, JZ, LLW, FLL, SL, LHZ); drafting of the manuscript (XC, JZ, LHZ); critical revision of the manuscript for important intellectual content (XC, JZ, LLW, SL, LHZ). All authors read and approved the final manuscript. The views expressed herein are those of the authors and not necessarily their institutions or sources of support.

\section{Acknowledgements}

We wish to thank the grant sponsors of this work, the National Science Foundation Council of China (30672119) and Guangdong Science Foundations (8151008901000028, 2008B050100011). We wish to thank Qun-Fang Yuan for skilful technical assistance.

\section{Author Details}

1Department of Anatomy, Zhong Shan School of Medicine; Sun Yat-Sen University, No. 74 Zhong shan Road 2, Guangzhou 510080, PR China and 2Department of Obesterics, the Third Affiliated Hospital; Sun Yat-Sen University, No. 74 Zhong shan Road 2, Guangzhou 510080, PR China

Received: 15 January 2010 Accepted: 24 May 2010

Published: 24 May 2010

\section{References}

1. Songcharoen $P$ : Management of brachial plexus injury in adults. Scand J Surg 2008, 97(4):317-323.

2. Holtzer CA, Marani E, Lakke EA, Thomeer RT: Repair of ventral root avulsions of the brachial plexus: a review. J Peripher Nerv Syst 2002 7(4):233-242.

3. McKay Hart A, Brannstrom T, Wiberg M, Terenghi G: Primary sensory neurons and satellite cells after peripheral axotomy in the adult rat: timecourse of cell death and elimination. Exp Brain Res 2002, 142(3):308-318

4. Wu W, Li L: Inhibition of nitric oxide synthase reduces motoneuron death due to spinal root avulsion. Neurosci Lett 1993, 153(2):121-124.

5. Novikov L, Novikova L, Kellerth JO: Brain-derived neurotrophic factor promotes axonal regeneration and long-term survival of adult rat spinal motoneurons in vivo. Neuroscience 1997, 79(3):765-774.

6. Drieu K: Preparation and definition of Ginkgo biloba extract. Presse Med 1986, 15(31):1455-1457.

7. van BeekTA: Ginkgolides and bilobalide: their physical, chromatographic and spectroscopic properties. Bioorg Med Chem 2005, 13(17):5001-5012

8. Pierre S, Jamme I, Droy-Lefaix MT, Nouvelot A, Maixent JM: Ginkgo biloba extract (EGb 761) protects $\mathrm{Na}, \mathrm{K}-\mathrm{ATPase}$ activity during cerebral ischemia in mice. Neuroreport 1999, 10(1):47-51.

9. Welt K, Fitzl G, Schaffranietz L: Myocardium-protective effects of Ginkgo biloba extract (EGb 761) in old rats against acute isobaric hypoxia. An electron microscopic morphometric study. II. Protection of microvascular endothelium. Exp Toxicol Pathol 1996, 48(1):81-86.

10. Szabo ME, Droy-Lefaix MT, Doly M, Braquet P: Free radical-mediated effects in reperfusion injury: a histologic study with superoxide 
dismutase and EGB 761 in rat retina. Ophthalmic Res 1991, 23(4):225-234.

11. Ahlemeyer B, Krieglstein J: Pharmacological studies supporting the therapeutic use of Ginkgo biloba extract for Alzheimer's disease. Pharmacopsychiatry 2003, 36(Suppl 1):S8-14.

12. Luo Y, Smith JV, Paramasivam V, Burdick A, Curry KJ, Buford JP, Khan I, Netzer WJ, Xu H, Butko P: Inhibition of amyloid-beta aggregation and caspase-3 activation by the Ginkgo biloba extract EGb761. Proc Natl Acad Sci USA 2002, 99(19):12197-12202.

13. Kobuchi H, Droy-Lefaix MT, Christen Y, Packer L: Ginkgo biloba extract (EGb 761): inhibitory effect on nitric oxide production in the macrophage cell line RAW 264.7. Biochem Pharmacol 1997, 53(6):897-903.

14. Calapai G, Crupi A, Firenzuoli F, Marciano MC, Squadrito F, Inferrera G, Parisi A, Rizzo A, Crisafulli C, Fiore A, et al: Neuroprotective effects of Ginkgo biloba extract in brain ischemia are mediated by inhibition of nitric oxide synthesis. Life Sci 2000, 67(22):2673-2683.

15. Zhou L, Wu W: Antisense oligos to neuronal nitric oxide synthase aggravate motoneuron death induced by spinal root avulsion in adult rat. Exp Neurol 2006, 197(1):84-92

16. Wu Y, Li Y, Liu H, Wu W: Induction of nitric oxide synthase and motoneuron death in newborn and early postnatal rats following spinal root avulsion. Neurosci Lett 1995, 194(1-2):109-112.

17. Wu W: Potential roles of gene expression change in adult rat spinal motoneurons following axonal injury: a comparison among c-jun, offaffinity nerve growth factor receptor (LNGFR), and nitric oxide synthase (NOS). Exp Neurol 1996, 141(2):190-200.

18. Li L, Wu W, Lin LF, Lei M, Oppenheim RW, Houenou LJ: Rescue of adult mouse motoneurons from injury-induced cell death by glial cell linederived neurotrophic factor. Proc Natl Acad Sci USA 1995, 92(21):9771-9775

19. DeFeudis F: Ginkgo biloba extract (EGb 761): from chemistry to the clinic. Ullstein Medical Wiesbaden 1998.

20. DeKosky ST, Fitzpatrick A, Ives DG, Saxton J, Williamson J, Lopez OL, Burke G, Fried L, Kuller LH, Robbins J, et al:: The Ginkgo Evaluation of Memory (GEM) study: design and baseline data of a randomized trial of Ginkgo biloba extract in prevention of dementia. Contemp Clin Trials 2006, 27(3):238-253.

21. Wang H, Long C, Duan Z, Shi C, Jia G, Zhang Y: A new ATP-sensitive potassium channel opener protects endothelial function in cultured aortic endothelial cells. Cardiovasc Res 2007, 73(3):497-503.

22. Zhou LH, Han S, Xie YY, Wang LL, Yao ZB: Differences in c-jun and nNOS expression levels in motoneurons following different kinds of axonal injury in adult rats. Brain Cell Biol 2008, 36(5-6):213-227.

23. Zhou LH, Wu W: Survival of injured spinal motoneurons in adult rat upon treatment with glial cell line-derived neurotrophic factor at 2 weeks but not at 4 weeks after root avulsion. J Neurotrauma 2006, 23(6):920-927.

24. Li R, Wang WQ, Zhang H, Yang X, Fan Q, Christopher TA, Lopez BL, Tao L, Goldstein BJ, Gao F, et al:: Adiponectin improves endothelial function in hyperlipidemic rats by reducing oxidative/nitrative stress and differential regulation of eNOS/iNOS activity. Am J Physiol Endocrinol Metab 2007, 293(6):E1703-1708.

25. Wu W, Li Y, Schinco FP: Expression of c-jun and neuronal nitric oxide synthase in rat spinal motoneurons following axonal injury. Neurosci Lett 1994, 179(1-2):157-161.

26. Ahlemeyer B, Krieglstein J: Neuroprotective effects of Ginkgo biloba extract. Cell Mol Life Sci 2003, 60(9):1779-1792.

27. Wang $Y$, Wang $L, W u J$ J, Cai J: The in vivo synaptic plasticity mechanism of EGb 761-induced enhancement of spatial learning and memory in aged rats. Br J Pharmacol 2006, 148(2):147-153.

28. Shen J, Wang J, Zhao B, Hou J, Gao T, Xin W: Effects of EGb 761 on nitric oxide and oxygen free radicals, myocardial damage and arrhythmia in ischemia-reperfusion injury in vivo. Biochim Biophys Acta 1998, 1406(3):228-236.

29. Sharma HS, Drieu K, Alm P, Westman J: Role of nitric oxide in blood-brain barrier permeability, brain edema and cell damage following hyperthermic brain injury. An experimental study using EGB-761 and Gingkolide B pretreatment in the rat. Acta Neurochir Supp/ 2000, 76:81-86.
30. Yu Y, Matsuyama Y, Nakashima S, Yanase M, Kiuchi K, Ishiguro N: Effects of MPSS and a potent iNOS inhibitor on traumatic spinal cord injury. Neuroreport 2004, 15(13):2103-2107.

31. Yang JY, Kim HS, Lee JK: Changes in nitric oxide synthase expression in young and adult rats after spinal cord injury. Spinal Cord 2007, 45(11):731-738.

32. Maitra I, Marcocci L, Droy-Lefaix MT, Packer L: Peroxyl radical scavenging activity of Ginkgo biloba extract EGb 761. Biochem Pharmacol 1995, 49(11):1649-1655.

33. Toda N, Ayajiki K, Okamura T: Cerebral blood flow regulation by nitric oxide in neurological disorders. Can J Physiol Pharmacol 2009, 87(8):581-594

34. De Palma C, Falcone S, Panzeri C, Radice S, Bassi MT, Clementi E: Endothelial nitric oxide synthase overexpression by neuronal cells in neurodegeneration: a link between inflammation and neuroprotection. J Neurochem 2008, 106(1):193-204.

35. Conti A, Miscusi M, Cardali S, Germano A, Suzuki H, Cuzzocrea S, Tomasello F: Nitric oxide in the injured spinal cord: synthases cross-talk, oxidative stress and inflammation. Brain Res Rev 2007, 54(1):205-218.

36. Kwak EK, Kim JW, Kang KS, Lee YH, Hua QH, Park TI, Park JY, Sohn YK: The role of inducible nitric oxide synthase following spinal cord injury in rat. J Korean Med Sci 2005, 20(4):663-669.

37. Oyama Y, Chikahisa L, Ueha T, Kanemaru K, Noda K: Ginkgo biloba extract protects brain neurons against oxidative stress induced by hydrogen peroxide. Brain Res 1996, 712(2):349-352.

38. Fu D, Ng YK, Gan P, Ling EA: Permanent occlusion of the middle cerebral artery upregulates expression of cytokines and neuronal nitric oxide synthase in the spinal cord and urinary bladder in the adult rat. Neuroscience 2004, 125(4):819-831.

doi: 10.1186/1749-7221-5-12

Cite this article as: Cheng et al., EGb761 protects motoneurons against avulsion-induced oxidative stress in rats Journal of Brachial Plexus and Peripheral Nerve Injury 2010, 5:12

\section{Submit your next manuscript to BioMed Central and take full advantage of:}

- Convenient online submission

- Thorough peer review

- No space constraints or color figure charges

- Immediate publication on acceptance

- Inclusion in PubMed, CAS, Scopus and Google Scholar

- Research which is freely available for redistribution
C) Biomed Central 